\title{
School Libraries in Evolving Education Systems: An Activity-Theoretical Approach
}

\author{
Eric M. Meyers \\ Doctoral Student \\ The Information School \\ University of Washington \\ USA
}

\begin{abstract}
Changes in educational policy and practice demand that we examine school library programs from a new perspective. As a model that takes a developmental view of minds in context, activity theory is particularly well suited to the study of school libraries and the learning that occurs therein. This paper presents an activitytheoretic model of the school library and delineates its elements and relationships. Case examples drawn from an ongoing study of libraries in the midst of school reform demonstrate the application of this framework and suggest how it may be employed to guide research and the development of library services and practices.
\end{abstract}

\section{Introduction}

School library programs are dynamic institutions which uniquely contribute to the success of children's learning (Todd \& Kuhlthau, 2005). The research of these institutions, however, has been inconsistent due to the lack of models or frameworks that describe the relationship between library programs, their contextual constraints, and the stated objective of schooling, namely student learning and subsequent demonstrated achievement. In light of changing educational policy and practice, a new, proactive agenda is required, one which focuses on how school libraries 1) can negotiate their provision and instruction goals in school contexts for maximum impact; 2) will adapt to evolving educational policy and practice; and 3) should provide agile and effective interventions that contribute to student achievement. This paper begins by presenting an activity-theoretical approach to examining school libraries which can be used to effectively frame issues in this domain, guide research investigations, and further the development of practices that will contribute to student achievement. Second, the paper will draw data from an ongoing 3-year study of secondary schools engaged in structural and curricular reform to illustrate the diverse ways activity theory can be used to identify tensions and contradictions in the library activity system. From an analysis of these contradictions and tensions, a new model of activity can be designed and implemented as part of a process of expansive learning (Engeström, 1991). The paper concludes with a call for continued study of activity theory as a potential framework for analyzing school library programs and services, and suggests some implications for this theory in professional practice. The activity-theoretic approach is both socially situated and culturally mediated; hence it is applicable to a wide range of school library programs, including those with distributed or circumstantially-unique elements.

\section{An Activity-Theoretical Model of School Libraries}

Activity theory (Leont'ev, 1979; 1981) originated within the socio-cultural/historical tradition of Soviet psychology. Drawing on the classical German philosophy from Kant to 
Hegel, and the writings of Marx and Engels, this theory focuses on the central issue of human action in context. Building on Vygotsky's (1978; 1986) work in semiotic mediation, Leont'ev expanded on this concept of cognitive activity to include both physical and psychological mediation. Researchers have noticed similarities between activity theory and Dewey's pragmatism as well as George Mead's symbolic interactionism (Engeström, 1999, Kuutti, 1996). While this concept has its roots in the early 20th century, a multidisciplinary and international community has sprung up around this theory in the present day, and its applications are found in education, sociology, psychology, anthropology, and humancomputer interaction. This theory has received little attention in the domain of information science (Hjørland, 1997; Spasser, 1999, 2002).

\section{The Activity Theory Framework}

Activity theory addresses human activities as they relate to artefacts, shared practices, and institutions, thus it goes beyond individual knowledge and decision making to take a developmental view of minds in context. As people work, play, think, and solve problems together they demonstrate an accumulated set of habits and values. Learning is not an isolated act; rather it is situated in time and space and influenced by the surrounding actors, resources, and behavioural constraints. One should also recognize that agents in the learning process, through their activities, influence the contexts in which such learning takes place. Activity theory, then, as a dynamic model, is particularly appropriate for the study of educational practice.

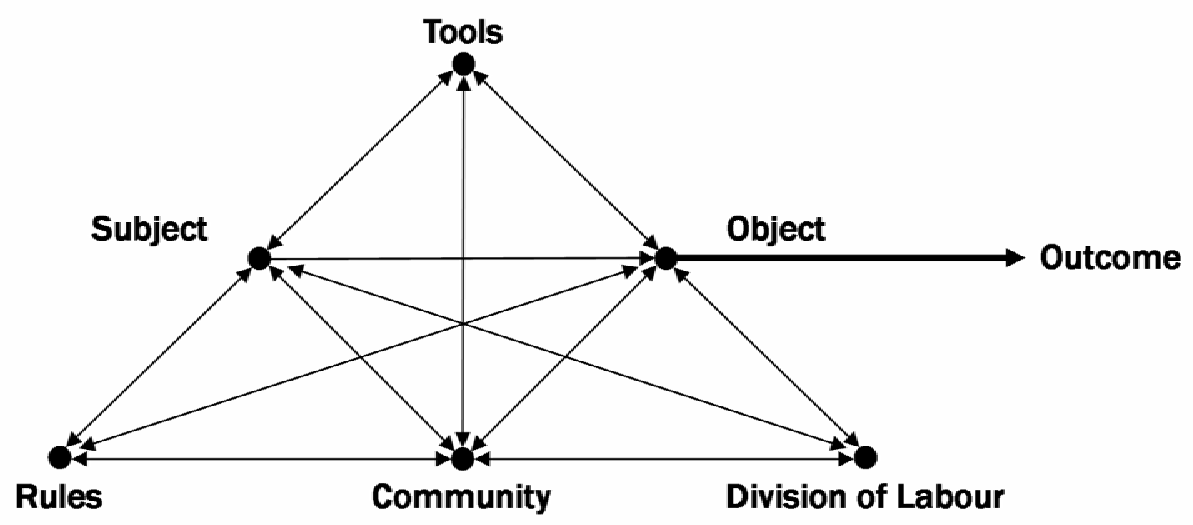

Figure 1: General activity theory model (based on Engeström, 1991)

The unit of analysis is defined as an activity, which includes a subject, object (as in an objective), meaningful context (community), and the mediational means (tools, rules, division of labour) by which the objective is achieved (Figure 1). Activity becomes the least meaningful context for understanding individual actions, but at a higher level it can be used to describe and evaluate systemic interactions and relationships. The systemic view of activity posits that each element is related to all other elements. An individual may be engaged in multiple activities simultaneously, which permits layers of activity that are interrelated or exclusive. The subject, or doer, of the activity can be a single person, group of persons, or a collective identity such as an institution or program. An activity is a form of doing directed at an object; we can distinguish among activities based on their objectives. Objectives are motivated by expected outcomes that derive from activity, and may be tangible or intangible - as tactile as physical artefacts or as amorphous as a common goal. 
While the subject works toward the object, the activity is contextually situated among other actors and institutions - the community. The remaining elements of the model - tools, rules, and division of labour - are concepts that mediate the relationships among the first three - the subject, object and community. Rules can be defined as the social norms or governing structure between a community and subject. Division of labour is the ways in which activity tasks toward achieving the objective are divided among the various stakeholders, including the subject and community members. Tools comprise the critical mediational means between the subject and object, and can be physical artefacts, symbols, or psychological scaffolds.

To understand individual activity, each of these elements and their relationships must be taken into account. A classic example from Leont'ev (1978) describes the method by which primitive peoples went about hunting game animals. The hunting group would be divided into two parts: the bush beaters, whose job was to frighten the game, and the catchers, who dispatched the creatures scared toward them by the bush beaters. The individual actions of a hunter with a stick thrashing a bush in isolation seem irrational, but placed within the activity of hunting they can be studied, understood and evaluated.

\section{School Library Activity Systems}

Activity theory offers a clear alternative to approaches which attempt to study individual library users, or the tools they use in the learning process, in isolation. If we apply the activity theory framework to our object of study, the school library, we can position the program as the subject of the system working toward the objective of student learning and subsequent achievement (Figure 2). In this process, the library program mediates the learning experience by means of its information literacy curriculum (the intellectual tool), as well as its facility, technology and material resources (physical tools). This activity takes place in the context of the school community composed of teachers, students, administrators, parents and other process stakeholders. The relationship between the library program and the community is mediated by the established system of governance and oversight (rules), social norms, schedules and contracts. The learning activity is also mediated by the different roles and responsibilities of the stakeholders in the process, both within the library program (instructor, reading advocate, CIO) and within the community itself - teachers teach, students learn, and they are divided into classes by grade and subject. Effective library activity is systematic and conditioned (that is, both afforded and constrained) by the related elements.

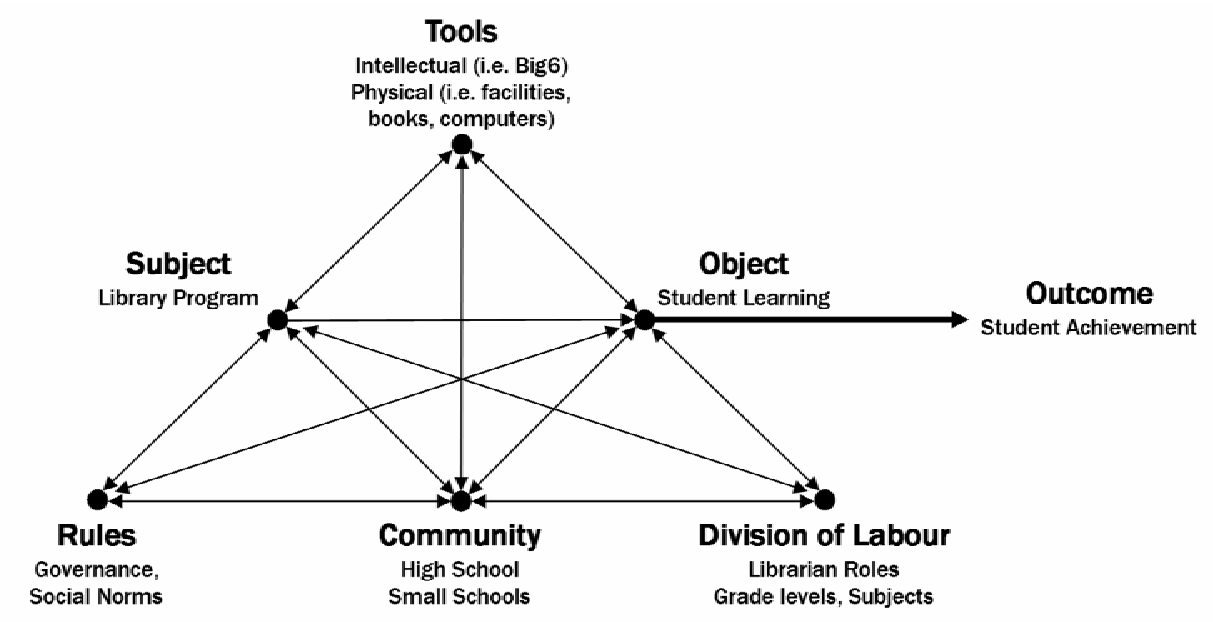

Figure 2: Activity-theoretic model of a school library program 
As this model rests on the assumption of the school itself as a dynamic system, much of its power as an explanatory framework rests in the concept of contradictions (Engeström, 1999). Contradictions arise when new ways of thinking or doing come in conflict with traditional or currently accepted ways of thinking and doing, and may occur within each of the elements, creating tensions between the elements in the system. Exaggerated contradictions, or those which reach crisis proportions, may result in a breakdown of the activity system itself. It is important to recognize that contradictions are not necessarily negative; rather, they are continually part of dynamic systems and a necessary component of learning. In distributed activity systems such as the school library, tensions are far from unusual. The ways in which we identify and manage those tensions determine whether they are resolved in a way that leads to continued development or continued tension and contradiction. In schools that experience structural or curricular change, we would expect that the new ways of teaching, learning, evaluating achievement, or even moving from class to class necessitate new relationships and conceptions of what school is and should be. These new conceptions and relationships may be positive in their intent, but will invariably conflict with the established cultural practices. Very often, in the course of everyday activities, tensions or breakdowns in activity will be repaired or negotiated, but not all tensions or contradictions are obvious to the actors engaged in a given activity (Blackler, 1995). Furthermore, actors may not share consistent motivations or conceptions, despite their participation in the same activity. Changing schools demand that the actors, institutions, and practices that compose the activity system make sense of these new relationships to ensure improved outcomes. Rather than seeing contradictions as adverse consequences, they provide a potential driving force for innovation and improvement of practices and services.

\section{Modeling Activity: Empirical Investigations of School Reform}

An activity theoretical lens for investigating school library programs focuses attention on what students, teachers, and librarians actually do in the learning context, as well as their conceptions of these activities, which can contain contradictions and resulting tensions. These contradictions become more salient or even exacerbated when changes occur in the larger learning environment, for example, in the course of reform efforts that seek to improve the quality of teaching and learning school-wide. The reform may also create new contradictions that were not present in the "old" way of thinking and doing. This can be illustrated with empirical case examples, which demonstrate how these reforms influence the complex relationships inherent in such institutions.

Learning in the school library is not simply a matter of individual students acquiring inert knowledge of specific domains, but rather is the development of specific cultural practices that rely on the rules, roles, and tools present in the learning context. The nature of "knowing" in the socio-cultural sense is collective, situated, and tentative (Cole \& Engeström, 1993). While all activity-theoretic approaches concur with this epistemological stance, there are two ways in which activity theory has been applied to learning domains (Blackler, 1995). These approaches are different, but not incompatible with the central tenets of Leont'ev's theoretical concepts (Zinchenko, 1995). The first of these focuses on the ways in which individuals develop common understanding of their practice through participation in shared activities (e.g. Hakkarainen, 1999; Lee, 2003). The second focuses on how group activity is conceived and is subsequently conditioned by the social, material and intellectual resources to which they have access (e.g. Engestrom et al, 2002; Spasser, 2002). The empirical investigation detailed here draws on this latter interpretation of the theory. 


\section{Background: The Small High School Libraries Project}

The Small High School Libraries Project is a three-year investigation of secondary school libraries in the midst of a specific structural and curricular reform effort. Through this reform, comprehensive high schools of 800-2000 students are being subdivided into autonomous academies or "small schools" of 400 students or less. This subdivision carries with it serious implications for the libraries of those schools. Small schools purportedly provide an improved learning environment that results in increased academic achievement, lowered dropout rates, and improved parent, teacher and student satisfaction with schooling. The small schools approach has the support of the United States Congress, the Department of Education, and the Bill \& Melinda Gates Foundation. Changing the size and nature of high schools also requires a change in the library program of those schools.

The teaching and learning approaches championed by small schools include: teachers personalizing instruction to facilitate student inquiry and to meet the needs of individual students; flexible curriculum focused on independent research; standards-based learning with intensive support to help students meet standards; and student demonstration of learning through projects, exhibitions and performance-based assessments. Teaching and learning in a small school requires that the library and librarian provide a rich infrastructure of information skills instruction and services, reading and literacy advocacy, information and technology services, and resources management.

Little attention has been given to the needs of small schools in terms of library and information services, systems, and resources, the role of teacher-librarians, or how to deploy library and information infrastructure effectively and efficiently. The project will determine the library information needs of small schools. Then it will create, implement, document, evaluate and disseminate models of exemplary library and information programs in multiplexes of smaller schools. The underlying assumption is that effective library and information services are essential for the successful education of adolescents in small schools. To learn more about the Small High School Libraries project at the University of Washington, visit: http://smallschools.ischool.washington.edu/

\section{Method of Empirical Investigation}

A triangulated, qualitative approach was used to develop a "comprehensive perspective" of the work life of librarians, the libraries they worked in, and their place in the school community (Patton, 2002 p.306). The data presented herein is drawn from interviews with administrators, librarians and classroom teachers, corroborated by over 100 hours spent observing the same librarians and classroom teachers as well as individual students and full classes engaged in activities within their high school libraries. This data was collected over a 16 month period, overlapping two academic years as part of a larger, three year project funded by the Institute for Museum and Library Studies. The field sites are six school libraries in the Puget Sound region of Washington (USA), representing a diverse sample of student and community demographics.

A goal of this study was to compare perceptions of the librarian to actual practice within school libraries. This required both interviews and in situ observations of various activities in the library. The observations, ranging from two to three hours apiece, were interspersed with in-depth interviews of the participating librarians. After observations of class visits to the library, classroom teachers were also interviewed. 
Activities in each of the participating libraries were observed at least four times at different times of day and different days of the week to permit study of a wide range of both student and adult activities. At least two instructional sessions with classes using library resources were included at each site. During the observations, class visits to the library were common. After these visits, one classroom teacher from each school agreed to be interviewed. The audio taped interviews were typically 30 minutes in length. These occurred within two days of the observation and included questions concerning: 1) their use of library resources; 2) collaboration activities with the librarian; 3) their perception of the role of the librarian and the library in the school's curriculum. For addition details on the method of investigation, see Meyers et al (2006).

\section{Historical Investigation}

The situated nature of activity systems indicates that they are rooted in historically developed and conditioned practices. In order to understand activity in the present, as well as guide its future development, one must have a clear idea of how the past has shaped these practices. The historical investigation for this project included interviews with administrators and school faculty concerning the school transformation process, both in general and specifically relating to the library program. Furthermore, a review of school reform literature allowed the investigators to analyze the reforms undertaken by the six schools in relation to similar reforms elsewhere. Gary Hartzell's (2000) report on the implications of select school reforms on library practices also influenced this investigation. In his report, Hartzell identifies a number of reform components that relate to the design and implementation of small learning communities. These reform components might be divided into 3 different categories: Governance, pedagogy, and technology. Other sources of contradictions that Hartzell and others have identified include issues of school culture that pervade both reform and non-reform settings. These components and their resulting contradictions are illustrated in Table 1.

\begin{tabular}{ll}
\hline School Component: & Resulting Contradiction: \\
\hline Governance & \\
Budget and staffing & Administrator led vs. teacher-led decision making \\
Scheduling & 7 period day vs. 3 or 4 period flexible block \\
Pedagogy & Student as passive recipient vs. Student as worker \\
Constructivist learning & Teacher as expert vs. Teacher as guide \\
Constructivist teaching & Generic vs. Individualized instruction \\
Personalization & Discrete lessons, units vs. Integrated lesson plans \\
Project-based learning & Subject areas as discrete vs. Subject areas related \\
Integrated instruction & Print vs. electronic sources (access) \\
Technology & Free web vs. Database collections (authority) \\
Computers/Internet & Student as novice vs. Student as expert \\
Computers/Internet & \\
Skills and aptitudes & Isolation vs. Collaboration \\
Culture & Librarian as support staff vs. Librarian as co-instructor \\
Teacher autonomy &
\end{tabular}

Table 1: Possible contradictions derived from historical analysis of reforms.

Not all of the contradictions will be present in all contexts, rather that these contradictions may be evident and more salient in contexts that undergo reform. Reform itself is an acknowledgement that the status quo is insufficient to meet the needs of the related stakeholders. The given reform, however, never replaces the existing ways of thinking and 
doing; instead it is combined and integrated in ways compatible with the context and stakeholders' needs. This constructed new replaces the given new, but not without the existence of contradiction and tension as students, teachers and administrators struggle to make sense of their new situation.

The two case examples which follow are drawn from the Small High School Library project data set to illustrate how some of these historically identified contradictions have become manifest in practice. Due to the space constraints of this paper, these examples will provide only a brief glimpse of the library activity systems of each school, but they are sufficient to elaborate for the reader how activity theory can model these contradictions in a way that provides direction to researchers and practitioners seeking to study and improve practice.

\section{Case Example: Spruce High School}

Ms. Stevens has been the librarian at Spruce High School for 13 years. During this span, the school has implemented a 4-period block schedule and is researching various academy structures and learning tracks to diversity and personalize the curriculum offerings. The library schedule, however does not match the school's schedule; each block is divided in half to allow more periods per day of library access. Ms. Stevens perceives herself as a constructivist educator, using her time with students to construct meaning from information, a process she calls "connecting the dots." In an interview with Ms. Stevens six months prior to the observation documented below she talked at length of her love of teaching. She particularly enjoys guiding students to resources where they get to solve problems, to help kids "find meaning through active learning." She explained that sometimes "this is not a traditional library.”

Ethnography of Trouble. Ms. Lewis’ 11th grade language arts class has scheduled two one-hour library sessions, during which time they will construct "future profiles" of themselves for their 10-year class reunion. The task invites students to imagine what their life will be in the future, and research specific aspects according to a rubric, including occupations, health, and where they will live. As the class enters and takes their seats at the library computers, Ms. Stevens, the librarian, asks that they begin at the library home page and select a specific database set from the menu. "This is better than Google. These databases will make you a smarter user," she tells them, without giving an explanation as to how this is so. She spends the next 12 minutes describing the contents of four different databases and how to use them. The last two focus on occupations, which seem to capture student interest, but the female students in the back row display impatience due to the time. "C'mon, we only got 31 more minutes." They glance repeatedly at the digital clock on the wall. Heavy sighs are heard as Ms. Stevens continues her directions. Soon after the class begins their explorations, Ms. Lewis confronts a student in the back row who is using Google to research her occupation. "Google is not a learning experience in the library - do not use it!” Ms. Stevens also rushes over, and together they argue with the student, who explains that she could not find information in the database concerning cosmetology training in Little Rock, Arkansas, which is what she would like to research. Ms. Stevens "must see for herself" and looks through the database only to find that the student is correct, only generic cosmetology information is available. The student is told that she must use the generic information instead since it is "more reliable." Other students are observed using Wikipedia. Ms. Stevens announces to the class that Wikipedia "is not entirely reliable. If you use it you'll need to verify the information with another source." The two adults seem pleased about the 
student progress, remarking that they are doing well, "now that we got them on [the correct source]." [At an observation in the same school two months prior, another class of students had been encouraged by Ms. Stevens to use the Wikipedia to research legal information for a different assignment.] In the second session, two days later, the same student who was researching cosmetology has a brief, but animated discussion with Ms. Lewis and Ms. Stevens about the validity of the information in the database. "The database is wrong!" she claims, showing that it does not list the proper name of her birthplace in the Virgin Islands.

Analyzing Contradictions. To learn new information seeking skills, students must first understand why previous habits may be inadequate to a given information task. At Spruce High, Ms. Stevens is attempting to support student searching by vetting the most appropriate sources. Students have a limited amount of time to complete their task, and immediately fall back to familiar sources when the librarian's choice does not meet their need. Despite her stated constructivist philosophy, the librarian does not explain why sources that students habitually use are deemed inappropriate to the task, and requires students to corroborate any information obtained from these sources. Students are pressed between their previous experience, time constraints, and the imposed parameters of the database with which they are unfamiliar, leading to resistance and dissatisfaction with the process and results.

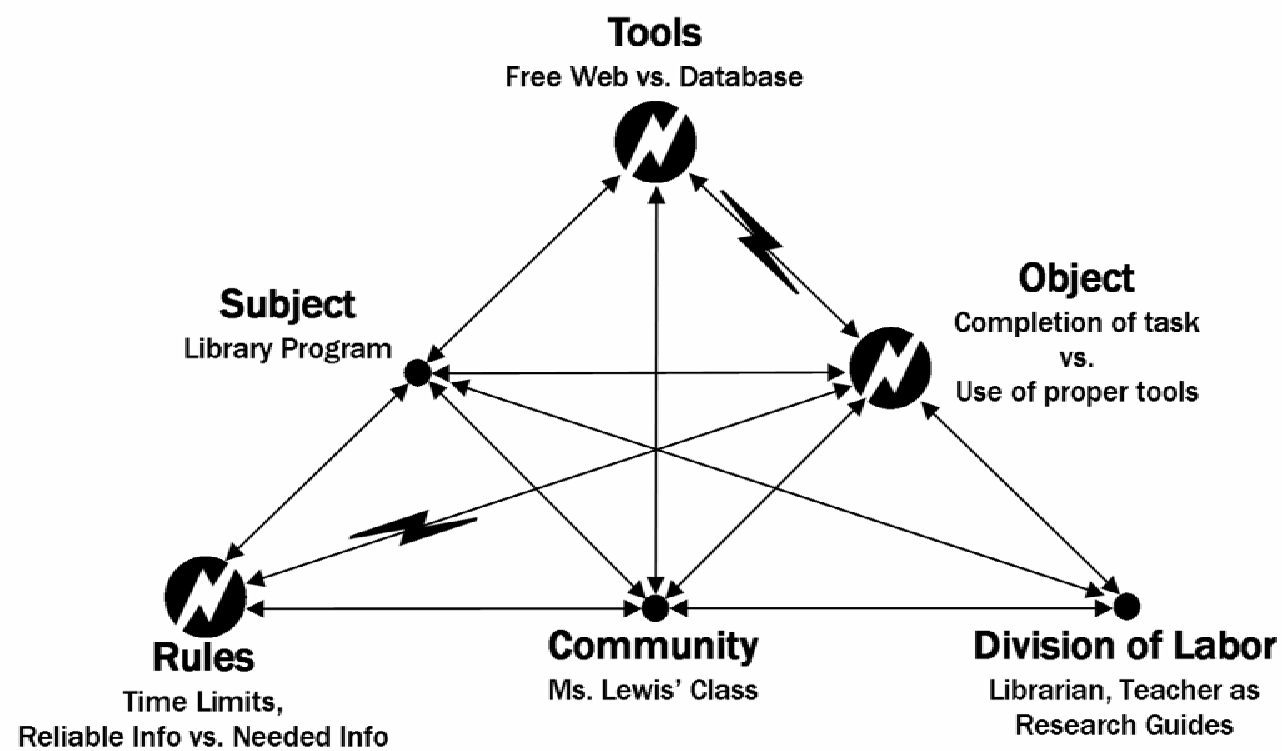

Figure 3: Contradictions present in class visit to the library.

We can identify contradictions at three points in the activity system (Figure 3). First, the students are conflicted over the use of tools: the database is not only inadequate for some of their search needs, but it is also a tool that requires new knowledge. The tools with which they are familiar are devalued and restricted during this activity. Second, the rules for completing the task call for students to make uncomfortable compromises: they must weigh the short amount of time given to work on the task against listening to the librarian's instruction, and they must sacrifice their information needs for what is available in the "reliable" database. These sets of contradictions and tensions create a contradiction at the object level for the students: is the point of the assignment to find the needed information or to learn to use the database? Since the contents of the database do not meet all of their needs, the outcome is dissatisfaction with the library tools and the mediational experience. Conflicted students either ignore the rules or attempt to undermine the validity of the 
privileged tool by finding inconsistencies within it. Salient during the entire activity is the sense of urgency created by the short research period, a product of historical tension between classroom teachers and the library program for access to its resources.

These contradictions are not critical to student success, but do point to some problems of practice that should be addressed. The librarian, despite her constructivist philosophy, does not take into account student skills and needs in scaffolding their research work. The librarian also provides conflicting information about tool use. Since the assignment mandates use of a tool to which students do not have access outside the library, the information seeking task is artificial and does not provide a point of transfer to real world tasks. Careful attention to assignment construction and some mediational coaching can help overcome these challenges. The schedule and time blocking issue will require classroom teachers to change their perceptions of access to the library. The current access schedule denies the pedagogical intent of the reform.

\section{Case Example: Redwood High School}

Ms. Reed has been the librarian at Redwood High School for 15 years, and has witnessed significant changes in teaching and learning since the school joined the Coalition of Essential Schools (CES). Redwood is gradually converting grade levels into academy groups, which are using team teaching methods, integrated curriculum, and a block schedule to facilitate a more personalized learning environment. As this process has progressed, she's noticed changes in the way the library is used, as well as teacher attitudes toward the research process.

Ethnography of Trouble. In nearly 20 hours of observation in the Redwood library, the researchers recorded only two class visits. During the remaining time the library was used by a small number of drop-in students, or by no one at all. Ms. Reed linked this change in the frequency of library use to the formation of the academy structure in the school:

"It started a few years ago when the small schools program was really getting under way and the $10^{\text {th }}$ grade academy was just starting. There was a large drop in the number of teachers bringing in their classes to work on reports here [the library] and dig through the references, the books, go through it all, talk about citations, the whole little quick reference thing...”

One of the pedagogical techniques being used by the teachers during this transition was the development of "focus folders" - photocopied articles that were pre-selected by the teachers to frame classroom discussion. This technique had become embedded in the practices of the school and its curriculum. Ms. Reed further explained: "The whole curriculum is geared towards the teachers doing the units, getting together and doing the research for them [the students] and then passing out the articles to the students." The emphasis by the classroom teachers had moved from the discovery of information through the research process to the analysis and synthesis of information from previously vetted sources. This was confirmed by our interviews with classroom teachers, one of whom remarked, "We don't have a lot of visits to the library." This teacher's discussion of the collaborative activities with the librarian illustrates this transformation:

"Another way that we have worked together in the past is when we did an integrative project for $10^{\text {th }}$ grade; this is a couple of years ago now, on globalization. We needed some background readings on different sorts of subjects and the TL did the research for us and put together packets so that was really helpful in terms of the project that we did.” 
Ms. Reed has also chosen to assume an added role in the school - that of technology coordinator. In this capacity, she administers and diagnoses problems with the computer and communication systems in the school, including teacher email. Because these tasks often require her to leave the library, she discourages the teachers from sending down large groups of students to use the space and resources when she cannot be present to help them. The move to a different mode of research and library usage has been reinforced by the librarian assuming a new role in the school. The lack of library usage is distressing to Ms. Reed, but she does not know how to alter the practice. "They used to have to come 4 or 5 times a semester but now the teachers just hand them the articles, which I have a hard time with, but that is what they do.” Furthermore, the school principal confided that she is disappointed with the current level of library use, and suggested that the librarian exacerbates this trend. In her analysis, the librarian "drives people to rely on online materials."

Analysis of Contradictions. At Redwood High School we have significantly different views of the research process, particularly what constitutes research and how students should be interacting with information. Ms. Reed enjoys the "messy" aspects of research, and feels that students gain a great deal from the search for reliable information. "Students may find something you don't like, but that's good - it's an important part of the research process." The teachers, on the other hand, view research as a means of analyzing and synthesizing data. While they rely on "background information" for their investigations, they see searching as a process that impedes or delays other processes. As a result the library is sorely underutilized, and its future as an institution in the school is in danger. Role adjustments have aggravated this contradiction nearly to the point of break down.
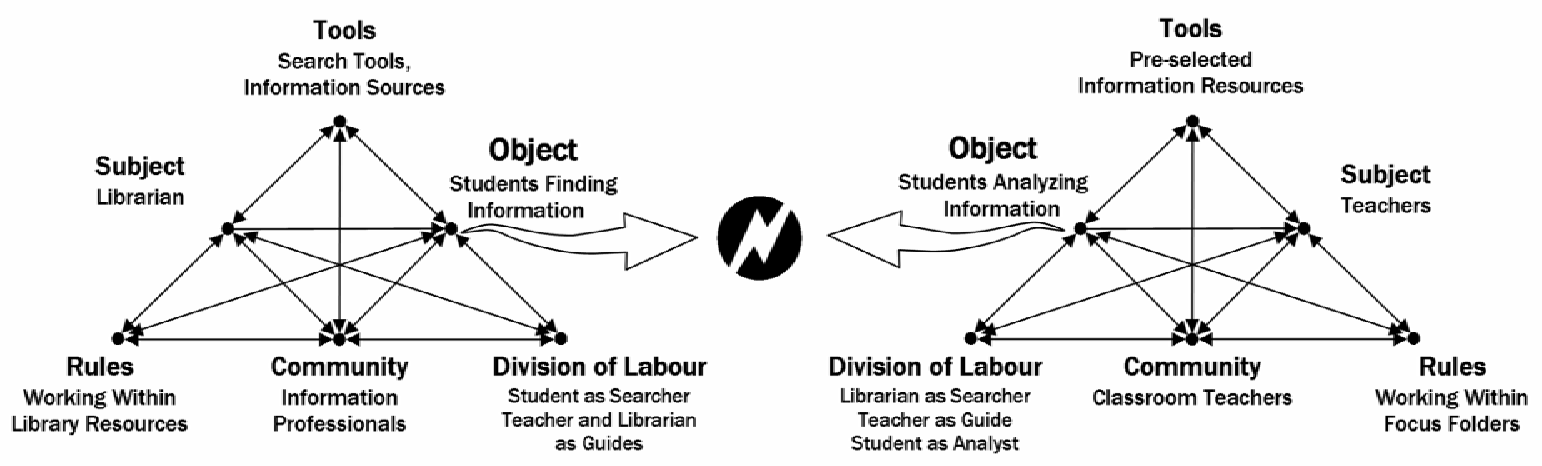

Figure 4: Lack of common object creates competing activity systems.

The library activity system and the teacher activity system do not have a common objective, that is, they have contradictory perceptions of the student outcome. This is what Hakkarainen (1999) calls the "common object problem" (Figure 4). The teachers have rejected the library activity system, and it does not contribute to student learning. The double bind of underutilization and associated role change have reinforced the opposing activity system, making change less likely to affect a return to the librarian's construction of the object - research as the process of tool selection, search, and relevance evaluation. When such a significant difference in meaning occurs, intervention will be necessary to move the systems closer together. Change on the part of the library may not be sufficient to influence the teacher's activity system. For the system to return to balance and a common object to take hold in practice, the teachers and librarian will need to develop a new way of conceiving research by viewing these processes as complementary, rather than contradictory. Key to returning balance will be eliminating the stand-off between these two systems through communication. 


\section{Using Activity Theory to Enact Change}

As previously discussed, activity theory is above all a model of change, one which holds the potential to drive innovation in practice. Identifying problems and contradictions is the diagnostic facet. To learn and grow, these diagnoses must be acted upon in context to form new practices and ways of looking at the world. The empirical cases presented above illustrate the beginning of this process of designing and implementing new practice to improve student learning through the school library. In this section I will outline the next steps in this project, detailing the expansive learning cycle and its relationship to activity theory.

\section{The Expansive Learning Cycle}

The activity theory framework can be used to make sense of both everyday and ongoing situations, disturbances and innovations in library practice. But beyond understanding the why and how of existing school library practice is the question of how we change and improve the work practitioners do in serving the needs of students and teachers. In the case of schools engaged in reform practice, that question becomes: How do school libraries adapt to evolving educational policies and practices at the school, district or even national level? How will school libraries, as dynamic agents of students' learning, respond to changing times?

Activity systems do not reside in a vacuum; rather they are constantly influenced by the conditions in which they reside, including other related activity systems, and the persons who engage in the activities themselves. The system is continually striving for balance while encountering tension and contradiction, hence it is a learning cycle not unlike Vygotsky's (1978) Zone of Proximal Development (ZPD). The research project described briefly in this paper is attempting to foster agile, adaptive library programs in the face of numerous contradictions, library programs that learn and grow as they encounter new ways of thinking and doing in the reform context. The "more capable peer," in the case of the Small High School Libraries project, is the research team itself, which is seeking to stimulate innovation and change in each of the six study schools. By working closely with the librarians, both as individuals and a community of practice, we hope to assist in the design of contextually situated best practices that may be applied and adapted to other schools facing similar change.

Figure 5 illustrates the expansive learning cycle employed by the research team. The project in the first 16 months has been engaged deeply in the first two steps in the cycle, during which time interviews and observations, what we have called the "ethnography of trouble," have helped us identify a number of contradictions and tensions. Combined with historical analysis of the reform process, both locally and on a broader plane, these empirical studies have helped us develop new models of library activity, specifically targeting the aspects of reform present in each school while supporting the existing roles and practices of the librarians that appear to work well. The librarians involved in the study have been instrumental in helping the team design and modify the proposed models of practice (Step 3). Implementation of these new models (Step 4) will occur in the coming year, with analysis of the effects to follow. 


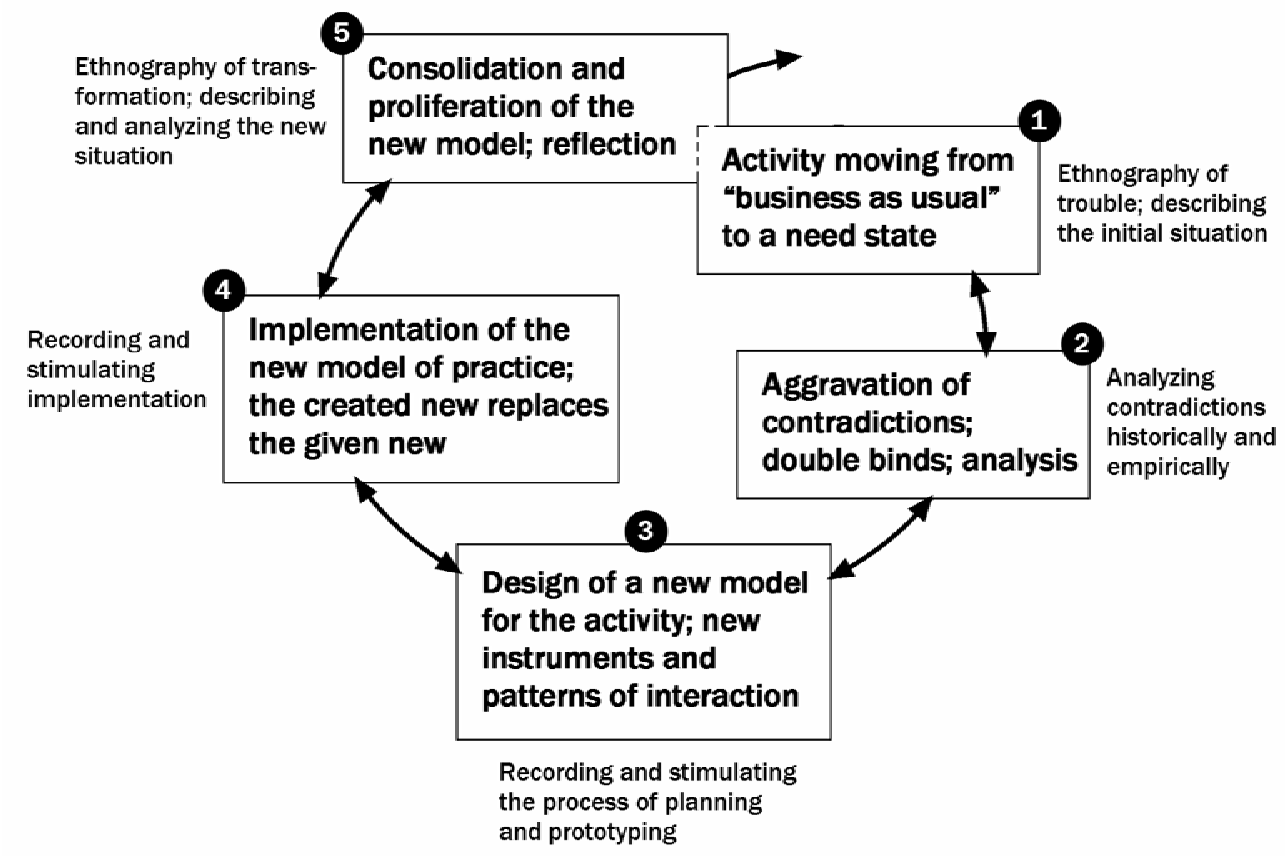

Figure 5. Expansive Learning Model (adapted from Engestrom, 1991)

The nature of this model of research is inherently interventionist. The project team, however, does not impose its new models on the research context, rather it stimulates implementation of new practices. These "given" practices will be adapted by the activity system as they come into conflict with existing practice, creating a new, and critically, socially constructed practice. Finally, the research team will engage in the ethnography of transformation (Step 5) in which it will describe the new practices that emerge from the research and suggest ways in which these practices might be adapted by other library programs.

\section{Implications for Future Study}

Recent research on the effectiveness of school library programs has been guided by the fundamental assumption that we all share: libraries and librarians play an important part in the teaching and learning of youth. Rather than rest on that assumption, however, researchers have designed studies to confirm that role and quantify its impact. The results of these studies have been presented to practitioners in ways that do not promote critical analysis of specific library programs and practices, but instead aggregate library activities, separate them from contextual factors, or minimize their active components. School libraries become a "black box" - students enter on one end and exit on the other more capable of achievement. The processes within the box become less important than the input and output, denying the importance of contextual factors, the active nature of library functions, and the diverse roles of trained librarians. Such research more ably maps where school libraries have been, rather then charting where they could be or what they could do. As educational policy and practice evolve, so too must libraries recognize the value of change and position themselves as vital, effective programs that both adapt to and lead new ways of teaching and learning. A novel way of looking at school library programs as dynamic institutions is required to move the agenda forward. 
One of the challenges that continues to plague practitioners and researchers is the application of theory to the practice of librarians in the field. Librarians need additional tools that will permit them to assess their own practice: identify areas of strength as well as diagnose areas of weakness and trouble, taking into account the larger school context. The next step in our project will include the design of an activity theory toolkit for use by school librarians, disseminated through workshops and facilitated by a community of practice model of professional learning (Wenger, 1998). Our research team has found that the development of communities of practice, bringing librarians together, virtually and physically, to work on designing new ways of conceiving and delivering information services in their schools, contributes significantly to elevating the conversation around effective library programs.

The activity-theoretic approach opens new possibilities for the study of library programs, youth information behaviour, and student learning as situated activity that is rooted in cultural practice. Beyond descriptive research, activity theory can be used to model and design new practices to respond to changing educational needs and constraints, as well as forecast the impact of proposed changes in educational systems. The integration of multiple dimensions of library processes in the concept of an activity system moves away from abstraction and isolation, and moves toward the prospect of directing change to facilitate more productive interactions and greater achievement.

\section{Acknowledgement:}

The author wishes to thank the members of the Small High School Libraries project team at the University of Washington Information School (Michael B. Eisenberg, Matthew Saxton, Lisa Nathan, Bryce Nelson, and Doug Erikson) for their support in the collection of the empirical data used in this paper.

\section{References}

Bellamy, R. K. (1996). Designing educational technology: computer-mediated change. In (B. Nardi, ed.) Context and consciousness. Cambridge, MA: The MIT Press.

Blackler, F. (1995). Knowledge, knowledge work and organizations: an overview and interpretation. Organization Studies, 16(6), 1021-1046.

Cole, M. and Engeström, Y. (1993). A cultural historical approach to distributed cognitions. In (G. Salomon, ed.) Distributed cognitions: Psychological and educational considerations, 1-46. NY: Cambridge University Press.

Engeström, Y. (1991). Developmental work research: Reconstructing expertise through expansive learning. In (M. Nurminen \& G. Weir, eds.) Human jobs and computer interfaces, 265-290. NY: North-Holland.

Engeström, Y. (1999). Activity theory and individual and social transformation. In (Engeström, et al, eds.) Perspectives on activity theory, 19-38. NY: Cambridge University Press.

Engeström, Y., Engeström, R. \& Suntio, A. (2002). Can a school community learn to master its own future? An activity-theoretical study of expansive learning among middle school teachers. In (G. Wells \& G. Claxton, eds.) Learning for life in the 21st Century, 211-224. Malden, MA: Blackwell.

Hakkarainen, P. (1999). Play and motivation. In (Engeström, et al, eds.) Perspectives on activity theory, 231249. NY: Cambridge University Press.

Hjørland, B. (1997). Information seeking and subject representation: An activity-theoretic approach to Information Science. Westport, CT: Greenwood Press. 
Kuutti, K. (1996). Activity theory as a potential framework for human-computer interaction research. In (B. Nardi, ed.) Context and consciousness. Cambridge, MA: The MIT Press.

Lee, C. D. (2003). Cultural modelling: CHAT as a lens for understanding instructional discourse based on African American English discourse patterns. In (Kozulin et al, eds.)Vygotsky's educational theory in cultural context, 393-410. NY: Cambridge University Press.

Leont'ev, A. M. (1978). Activity, consciousness and personality. Englewood Cliffs, NJ: Prentice-Hall.

Leont'ev, A. M. (1981). The problem of activity in psychology. In (J. Wertsch, trans. and ed.) The concept of activity in Soviet psychology, 37-70. Armonk, NY: M.E. Sharpe.

Luria, A. R. (1981). Language and cognition. (J. Wertsch, trans. and ed.) NY: Wiley Intersciences.

Meyers, E. M., Nathan, L. P \& Saxton, M. L. (2006). Barriers to information seeking in school libraries: Examining constraints to intermediation. Article accepted for publication.

Patton, M. Q. (2002). Qualitative research and evaluation methods. 3rd Edition. Thousand Oaks, CA: Sage.

Spasser, M. A. (1999) Informing information science: The case for activity theory. Journal of the American Society for Information Society, 50(12), 1136-1138

Spasser, M. A. (2002). Realist Activity Theory for Digital Library Evaluation: Conceptual Framework and Case Study. Computer Supported Cooperative Work, 11(1/2), 81-110.

Todd, R. \& Kuhlthau, C. (2005). Student learning through Ohio school libraries, part 1: How effective school libraries help students. School Libraries Worldwide (11):1, 63-88.

Vygotsky, L. S. (1978). Mind in society: The development of higher psychological processes. Cambridge, MA: Harvard University Press.

Vygotsky, L. S. (1986). Thought and language. (A. Kozulin, trans. and ed.) Cambridge, MA: The MIT Press.

Wells, G. (2000). Dialogic inquiry in education: Building on the legacy of Vygotsky. In (C. D. Lee \& P. Smagorinsky, eds.) Vygotskian perspectives on literacy research: Constructing meaning through collaborative inquiry, 51-85. NY: Cambridge University Press.

Wenger, E. (1998). Communities of practice: Learning, meaning and identity. NY: Cambridge University Press.

Zinchenko, V. P. (1995). Cultural-historical psychology and the psychological theory of activity: retrospect and prospect. In (J. Wertsch et al, eds.) Sociocultural studies of mind, 37-55. NY: Cambridge University Press.

\section{Author Note:}

Eric M. Meyers is a doctoral student at the University of Washington, where he studies youth information behavior and information fluency in formal and informal contexts. He holds Masters Degrees in Information and Education from the University of Michigan and Stanford University respectively. Formerly a teacher, school librarian, and technologist, he consults with school professionals on information services, library spaces, and technology curriculum. 
Reproduced with permission of the copyright owner. Further reproduction prohibited without permission. 